\title{
Study of Thermal Properties of Mixed (PP/EPR)/ABS with Five Model Compatibilizers
}

\author{
Pierre Marcel Anicet Noah, ${ }^{1}$ Louis-Max Ayina Ohandja, ${ }^{1}$ Rolant Eba Medjo, ${ }^{2}$ \\ Salem Chabira, ${ }^{3}$ Fabien Betene Ebanda, ${ }^{1}$ and Patrick Anyouzoa Ondoua ${ }^{1}$ \\ ${ }^{1}$ Laboratory of Mechanics, Materials, Structure and Production, Faculty of Science, University of Douala, P.O. Box 24157, \\ Douala, Cameroon \\ ${ }^{2}$ Fundamental Physics Laboratory, Department of Physics, Faculty of Science, University of Douala, P.O. Box 24157, Douala, Cameroon \\ ${ }^{3}$ Mechanics Laboratory (lme), Rheology of Thin Films and Environment, University of Laghouat, Laghouat, Algeria
}

Correspondence should be addressed to Pierre Marcel Anicet Noah; noahpierre@yahoo.fr

Received 26 September 2015; Revised 20 December 2015; Accepted 29 December 2015

Academic Editor: Runcang Sun

Copyright (C) 2016 Pierre Marcel Anicet Noah et al. This is an open access article distributed under the Creative Commons Attribution License, which permits unrestricted use, distribution, and reproduction in any medium, provided the original work is properly cited.

\begin{abstract}
The influences of incorporating compatibilizers E-EA-MAH, E-MA-GMA, E-AM, SEBS KRATON G, or PP-g-MAH on the thermal properties of mixed (polypropylene/ethylene propylene rubber)/acrylonitrile butadiene styrene (PP/EPR)/ABS have been investigated. DSC investigations have revealed that the incorporation of $5 \%$ of ABS in the copolymer (PP/EPR) does not fundamentally affect the thermal properties of the basic copolymer; additionally, the addition of $1.5 \%$ of each of the compatibilizers in the basic mixture does not significantly alter the crystallization temperature values and the melting of the -P- sequences. There is a variation of melting enthalpy values of the -P- sequences of $18.23 \%$ using SEBS KRATON G and of $10.38 \%$ using E-AM-GMA. When the rate of each of the compatibilizers increases to $5 \%$, overall crystallization enthalpies of -P- sequences are almost kept unchanged, except for the case of using the compatibilizer E-AM-GMA with a variation of $8.42 \%$. There is a minor variation of the melting enthalpy of -P- sequences with higher levels of compatibilizer. The incorporation of 5\% ABS copolymer in the PP/EPR does not significantly alter the thermal properties of the basic structure of (PP/EPR)/ABS.
\end{abstract}

\section{Introduction}

Polymer industries have known fantastic development in the middle of the last century, where many manufactures have developed new plastic kinds. The production of new polymers such as thermoplastics, thermosets, or rubbers required large investments in research to find the way to produce them chemically. The design of new chemical vessels, the synthesis of new monomers prepared via complex chemical ways and methods, and the finding of new type of catalysts have contributed to the expansion of the plastic industry [1]. However, this approach was excessively expensive for the plastic industries. This is why the development of new plastic materials has been relayed by the blending of different kinds of polymers. This new way uses additive reinforcing or improving compatibilizers between the constituting products. This way of producing new type of plastic materials is less expensive. Nowadays, polymer blends are about $30 \%$ of the total plastic world consumption. The tendency continues to increase regularly from year to year [2-5]. The main problem encountered by manufacturer in mixing polymers is their nonmiscibility. The solution of this problem consists in adding a third element called compatibilizer. This product is also called coupling agent, adhesion promoter, or interfacial agent [6-9]. The characteristics of the different mixtures are as follows: the copolymer PP/EPR, used as a template, is mainly a combination of two components, propylene and ethylene, in proportions of 78 and $22 \%$, respectively [9]. Commercially, this template is available as granules. This product is prepared using injection molding articles. The copolymer PP/EPR used displays excellent impact properties and very good adhesion as substrate. This helps the flowing of the melt during processing. The combination of these properties makes the basic copolymer PP/EPR very attractive 
TABLE 1: ABS characteristics.

\begin{tabular}{lccc}
\hline Properties & Values & Unit & Test method \\
\hline Density & 1.05 & - & - \\
Melt flow index & 10 & $\mathrm{~g} / 10 \mathrm{~min}$ & MFI \\
Young's modulus & 1 & $\mathrm{GPa}$ & Traction \\
Deformation at yield & 2 & $\%$ & Traction \\
Maximum stress & 20 & $\mathrm{MPa}$ & Traction \\
\hline
\end{tabular}

especially for specific applications such as bumpers. Moreover, the basic copolymer PP/EPR is highly UV stabilized (incorporation of UV stabilizers before processing); it can be used as bumper even unpainted. Compatibilizers often used are E-EA-MAH, E-MA-GMA, E-AM, SEBS KRATON G, or PP-g-MAH in the mixture of copolymer PP/EPR and ABS.

The present work studies the effect on a thermal point of view of commercial compatibilizers in mixture with copolymers PP/EPR and ABS. It starts with Introduction which is followed by Materials and Methods. The third section deals with the results. The next two sections are Discussion and Conclusions.

\section{Materials and Methods}

2.1. Materials. The ABS used was a thermoplastic elastomer compound technology (butadiene) dispersed and grafted as minor phase in a thermoplastic matrix of the copolymer of styrene and acrylonitrile SAN [10]. The ABS resin contains $60 \%$ styrene, $27 \%$ acrylonitrile, and $13 \%$ butadiene; it is a well-known commercial polymer for its excellent mechanical properties [11, 12]. It is produced by the supplier Lustran Polymer $^{\circledR}$ under reference "Lustran ABS 2710." ABS characteristics are reported in Table 1. Butadiene nodules act as impact modifiers, $250 \mathrm{~kJ} / \mathrm{m}^{2}$ [13], and provide good mechanical properties to the material. Figures 1 and 2 represent DSC curves of PP/EPR and ABS copolymers, respectively.

Lotader AX8900 is an ethylene (E)/methyl acrylate (MA)/glycidyl methacrylate (GMA), which contains $8 \%$ in weight of GMA. Lotader AX3210 is a terpolymer of ethylene (E), acrylic ester (AE), and Maleic Anhydride (MAH). It contains 3\% in weight of Maleic Anhydride. It is marketed by Atofina; its characteristics are presented in Table 2 .

LOTRYL 20MA08 ECH is an ethylene/acrylate methyl (E-AM), containing $20 \%$ acrylate methyl in weight. It is soluble in chloroform $\mathrm{CHCl}_{3}$. Ethylene is compatible with the polypropylene and acrylate methyl is compatible with the styrene portion of the ABS. SEBS KRATON G is a triblock copolymer poly(styrene-b-ethylene-co-butylene-b-styrene). It is compatible with $\mathrm{ABS}$ and polypropylene; it is also soluble in chloroform $\mathrm{CHCl}_{3}$. OREVAC CA 100 is a polypropylene chemical function containing a high percentage of Maleic Anhydride. Its characteristics are shown in Table 3.

The HAAKE PolyLab System mixer is connected to a computer. The "PolyLab" software controls the experimental procedure (screw types, mold temperature, screw speed, and holding time, etc.) and it records automatically all the data.

2.2. Methods. The blends are prepared by means of an internal mixer HAAKE PolyLab System. A computer is controlling
TABLE 2: Characteristics of compatibilizer E-EA-MAH.

\begin{tabular}{lccc}
\hline Specifications & Values & Unit & Test method \\
\hline $\begin{array}{l}\text { Melt flow index } \\
\left(190^{\circ} \mathrm{C} / 2.16 \mathrm{~kg}\right)\end{array}$ & 5 & $\mathrm{~g} / 10 \mathrm{~min}$ & ASTM D 1238/ISO1133 \\
Percentage of copolymer & 9 & $\%$ & $\mathrm{IR}$ \\
Density to $23^{\circ} \mathrm{C}$ & 0.94 & $\mathrm{~g} / \mathrm{cm}^{3}$ & ASTM D 1505 \\
Fusion point & 107 & ${ }^{\circ} \mathrm{C}$ & DSC \\
Vicat softening point & 80 & ${ }^{\circ} \mathrm{C}$ & ASTM D 1525/ISO306 \\
$\begin{array}{l}(1 \mathrm{~kg}) \\
\text { Flexural modulus }\end{array}$ & 120 & $\mathrm{MPa}$ & ASTM D 790/ISO178 \\
Deformation at yield & 600 & $\%$ & ASTM D 638/ISOR527 \\
\hline
\end{tabular}

TABLE 3: Characteristics of the compatibilizer PP-g-MAH.

\begin{tabular}{lccc}
\hline Specifications & Values & Unit & Test method \\
\hline Melt flow index $\left(190^{\circ} \mathrm{C} / 325 \mathrm{~g}\right)$ & 10 & $\mathrm{~g} / 10 \mathrm{~min}$ & - \\
Fusion point & 167 & ${ }^{\circ} \mathrm{C}$ & $\mathrm{DSC}$ \\
Vicat softening point $(1 \mathrm{~kg})$ & 147 & ${ }^{\circ} \mathrm{C}$ & ISO306 $(9.81 \mathrm{~N})$ \\
Flexural modulus & 880 & $\mathrm{MPa}$ & ISO 178 \\
Yield stress & 22 & $\mathrm{MPa}$ & - \\
Percent elongation & 12 & $\%$ & - \\
Point of embrittlement & $<-50$ & ${ }^{\circ} \mathrm{C}$ & ASTM D 726 \\
\hline
\end{tabular}

the rotation of the screw and the heating temperature. The variation of the torque exerted by the screws "rollers" mixer is expressed as function of time. The rotation of the screw is adjusted to $40 \mathrm{RPM}$ (round per minute) at a temperature of $180^{\circ} \mathrm{C}$ during 20 minutes. Thermal tests are performed by DSC according to a controlled procedure. A DSC test is performed on the copolymer PP/EPR to get the initial values of the thermal constants. The second step consists in mixing PP/EPR with $5 \%$ of $\mathrm{ABS}$ and getting its thermal constants using the same experimental procedure. To highlight the effects of the addition of ABS to the copolymer $\mathrm{PP} / \mathrm{EPR}$, one can simply compare the thermal constants of the two mixtures. If these results are relatively equal, it can be considered that the addition of 5\% ABS copolymer does not alter the thermal properties of the latter. The same experimental procedure is applied to determine the thermal effect of the five above-mentioned compatibilizers on mixtures (PP/EPR)/ABS containing 5\% ABS, with a rate of $1.5 \%$ or $5 \%$ compatibilizer. The dispersion of low mass rate not exceeding $4 \%$ of compatibilizers in the mixture is widely enough to generate physical or chemical interactions required at the interface between the two phases of the mixture, which may cause good properties impact of material [14, 15]. 50 grams of each mixture is prepared. Tables 4 and 5 present the composition of the mixtures used.

For all the tests, the samples were subjected twice to the following thermal cycle: $-100^{\circ} \mathrm{C}$ to $200^{\circ} \mathrm{C}$ with a heating rate of $10^{\circ} \mathrm{C} / \mathrm{min}$ and an isothermal holding at $200^{\circ} \mathrm{C}$ for 2 minutes and then to cooling from $200^{\circ} \mathrm{C}$ to $-100^{\circ} \mathrm{C}$ with a cooling rate of $-10^{\circ} \mathrm{C} / \mathrm{min}$ with an isothermal holding for 2 minutes at $-100^{\circ} \mathrm{C}$. All the data are automatically recorded. The thermal transitions of the sample are identified according 
TABLE 4: Composition of blends (PP/EPR)/ABS/compatibilizer at a rate of $1.5 \%$ of one of the five compatibilizers.

\begin{tabular}{|c|c|c|c|c|c|c|c|}
\hline Mixtures & $\mathrm{PP} / \mathrm{EPR}$ & $\mathrm{ABS}$ & E-AM-GMA & E-EA-MAH & PP-g-MAH & SEBS & E-AM \\
\hline (PP/EPR)/ABS/E-AM-GMA & $93.5 \%$ & $5.0 \%$ & $1.5 \%$ & - & - & - & - \\
\hline (PP/EPR)/ABS/E-EA-MAH & $93.5 \%$ & $5.0 \%$ & - & $1.5 \%$ & - & - & - \\
\hline (PP/EPR)/ABS/PP-g-MAH & $93.5 \%$ & $5.0 \%$ & - & - & $1.5 \%$ & - & - \\
\hline (PP/EPR)/ABS/SEBS & $93.5 \%$ & $5.0 \%$ & - & - & - & $1.5 \%$ & - \\
\hline (PP/EPR)/ABS/E-AM & $93.5 \%$ & $5.0 \%$ & - & - & - & - & $1.5 \%$ \\
\hline
\end{tabular}

TABLE 5: Composition of blends (PP/EPR)/ABS/compatibilizer at a rate of $5 \%$ of one of the five compatibilizers.

\begin{tabular}{|c|c|c|c|c|c|c|c|}
\hline Mixtures & $\mathrm{PP} / \mathrm{EPR}$ & ABS & E-AM-GMA & E-EA-MAH & PP-g-MAH & SEBS & E-AM \\
\hline (PP/EPR)/ABS/E-AM-GMA & $90.0 \%$ & $5.0 \%$ & $5.0 \%$ & - & - & - & - \\
\hline (PP/EPR)/ABS/E-EA-MAH & $90.0 \%$ & $5.0 \%$ & - & $5.0 \%$ & - & - & - \\
\hline (PP/EPR)/ABS/PP-g-MAH & $90.0 \%$ & $5.0 \%$ & - & - & $5.0 \%$ & - & - \\
\hline (PP/EPR)/ABS/SEBS & $90.0 \%$ & $5.0 \%$ & - & - & - & $5.0 \%$ & - \\
\hline (PP/EPR)/ABS/E-AM & $90.0 \%$ & $5.0 \%$ & - & - & - & - & $5.0 \%$ \\
\hline
\end{tabular}

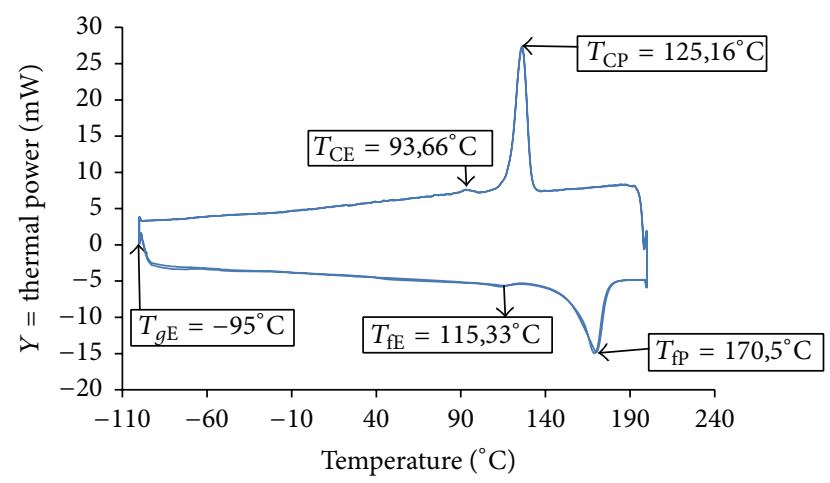

PP/EPR

FIGURE 1: DSC curve of the copolymer PP/EPR used.

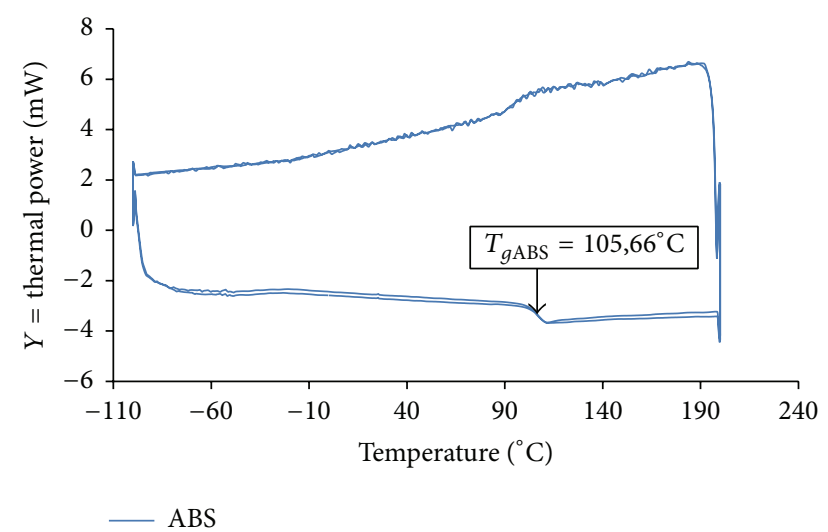

FIGURE 2: DSC curve of the copolymer ABS used.

to an internal reference subjected to the same temperature cycles. The sample and the reference are in the same furnace and the temperature varies linearly with time. Once the sample reaches a transition, the difference in temperature between the sample and the reference is compensated by the heating device. This appears on the DSC curve as a small drop of the base line for minor transition as glass transition temperature or a broad endothermic peak for the fusion. The DSC set-up is composed of a measurement chamber and a computer. Two pans are heated in the measurement chamber. The sample pan contains the material being investigated. A second pan, typically empty, is used as a reference.

The experiment is carried out in inert atmosphere (argon) to avoid a material reaction with air. The measurements are performed with a DSC 30 maintained by Mettler-Toledo SA system. The equipment is calibrated with indium, zinc, and lead: the calibration check is done with indium $\left(T_{m}=\right.$ $156.6^{\circ} \mathrm{C} \pm 0.5^{\circ} \mathrm{C} ; \Delta \mathrm{H}=28.45 \mathrm{~J} / \mathrm{g} \pm 0.5 \mathrm{~J} / \mathrm{g}$ ). Few $\mathrm{mg}$ of the sample $(<20 \mathrm{mg})$ are introduced into a $40 \mu \mathrm{L}$ aluminum capsule with a perforated lid. The weight is controlled with a Mettler-Toledo balance of $\pm 1 \mu \mathrm{g}$ in accuracy.

\section{Results}

The DSC curves of PP/EPR and ABS, respectively, are represented in Figures 1 and 2. Figure 1 shows different thermal transitions. The most important of them is the crystalline phase melting at $170^{\circ} \mathrm{C}$. Figure 2, showing the ABS DSC curve, does not have crystalline phases because of the absence of the crystalline fusion. The thermal properties of the respective copolymers and mixtures are reported in Table 6. The effects of the compatibilizers' concentration added to the $\mathrm{PP} / \mathrm{EPR}$ and ABS mixture on the torque during mixing are represented in Figures 3 and 4.

All the DSC curves of the copolymers PP/EPR and ABS with compatibilizer in mixture at the rate of $1.5 \%$ and $5 \%$ are reported from Figures 5-12. Their thermal properties for second thermal cycles are shown in Tables 7 and 8.

In amorphous statistical copolymers, $T_{g}$ is usually a monotonic function of the composition of different copolymers constituting the mixture $[16,17]$. The most commonly used relationship to predict $T_{g}$ of a mixture of the copolymers is the Fox equation [18-20],

$$
\frac{1}{T_{g}}=\frac{w_{1}}{T_{g_{1}}}+\frac{w_{2}}{T_{g_{2}}},
$$


TABLE 6: Thermal characteristics of copolymers PP/EPR and ABS and their mixture (PP/EPR)/ABS.

\begin{tabular}{lccccccc}
\hline Mixtures & $T_{g \mathrm{ABS}}\left({ }^{\circ} \mathrm{C}\right)$ mid-point & $T_{\mathrm{fE}}\left({ }^{\circ} \mathrm{C}\right)$ & $T_{\mathrm{fP}}\left({ }^{\circ} \mathrm{C}\right)$ & $T_{\mathrm{CE}}\left({ }^{\circ} \mathrm{C}\right)$ & $T_{\mathrm{CP}}\left({ }^{\circ} \mathrm{C}\right)$ & $\Delta \mathrm{Hf}_{p}\left(\mathrm{~J} / \mathrm{g}_{\mathrm{PP}}\right)$ & $\Delta \mathrm{HC}_{p}\left(\mathrm{~J} / \mathrm{g}_{\mathrm{PP}}\right)$ \\
\hline $\mathrm{PP} / \mathrm{EPR}$ & - & 115.33 & 170.5 & 93.66 & 125.16 & -103.78 & 106.17 \\
$\mathrm{ABS}$ & 105.7 & - & - & - & - & - & - \\
$(\mathrm{PP} / \mathrm{EPR}) / \mathrm{ABS}$ & 105.7 & 116.16 & 170.83 & 93.00 & 124.83 & -104.84 & 106.59 \\
\hline
\end{tabular}

$\Delta \mathrm{Hf}_{p}$ : melting enthalpy of the isotactic polypropylene sequences (-P-) of the basic copolymer PP/EPR.

$\Delta \mathrm{HC}_{p}$ : crystallization enthalpy of the isotactic polypropylene sequences (-P-) of the basic copolymer PP/EPR.

TABLE 7: Thermal characteristics of the blends (PP/EPR)/ABS/compatibilizer at rate of $1.5 \%$ of each one of the five compatibilizers.

\begin{tabular}{lccccccc}
\hline Mixtures & $T_{g \mathrm{ABS}}\left({ }^{\circ} \mathrm{C}\right)$ mid-point & $T_{\mathrm{fE}}\left({ }^{\circ} \mathrm{C}\right)$ & $T_{\mathrm{fP}}\left({ }^{\circ} \mathrm{C}\right)$ & $T_{\mathrm{CE}}\left({ }^{\circ} \mathrm{C}\right)$ & $T_{\mathrm{CP}}\left({ }^{\circ} \mathrm{C}\right)$ & $\Delta \mathrm{Hf}_{p}\left(\mathrm{~J} / \mathrm{g}_{\mathrm{PP}}\right)$ & $\Delta \mathrm{HC} p\left(\mathrm{~J} / \mathrm{g}_{\mathrm{PP}}\right)$ \\
\hline (PP/EPR)/ABS & 105.7 & 116.16 & 170.83 & 93.00 & 124.83 & -104.84 & 106.59 \\
$(\mathrm{PP} / \mathrm{EPR}) / \mathrm{ABS} / \mathrm{E}-\mathrm{AM}-\mathrm{GMA}$ & 105.7 & 119.33 & 170.33 & 95.83 & 125.83 & -93.96 & 104.69 \\
$(\mathrm{PP} / \mathrm{EPR}) / \mathrm{ABS} / \mathrm{E}-\mathrm{EA}-\mathrm{MAH}$ & 105.7 & 111.33 & 168.83 & 95.66 & 127.32 & -97.67 & 101.09 \\
$(\mathrm{PP} / \mathrm{EPR}) / \mathrm{ABS} / \mathrm{PP}-\mathrm{g}-\mathrm{MAH}$ & 105.7 & 118.16 & 170.16 & 95.33 & 126.33 & -105.41 & 97.43 \\
$(\mathrm{PP} / \mathrm{EPR}) / \mathrm{ABS} / \mathrm{SEBS}$ & 105.7 & - & 170.16 & 94.33 & 125.83 & -85.73 & 107.28 \\
$(\mathrm{PP} / \mathrm{EPR}) / \mathrm{ABS} / \mathrm{E}-\mathrm{AM}$ & 105.7 & 112.66 & 171.00 & 94.33 & 126.5 & -92.68 & 109.05 \\
\hline
\end{tabular}

$\Delta \mathrm{Hf}_{p}$ : melting enthalpy of the isotactic polypropylene sequences (-P-) of the basic copolymer PP/EPR.

$\Delta \mathrm{HC}_{p}$ : crystallization enthalpy of the isotactic polypropylene sequences (-P-) of the basic copolymer PP/EPR.

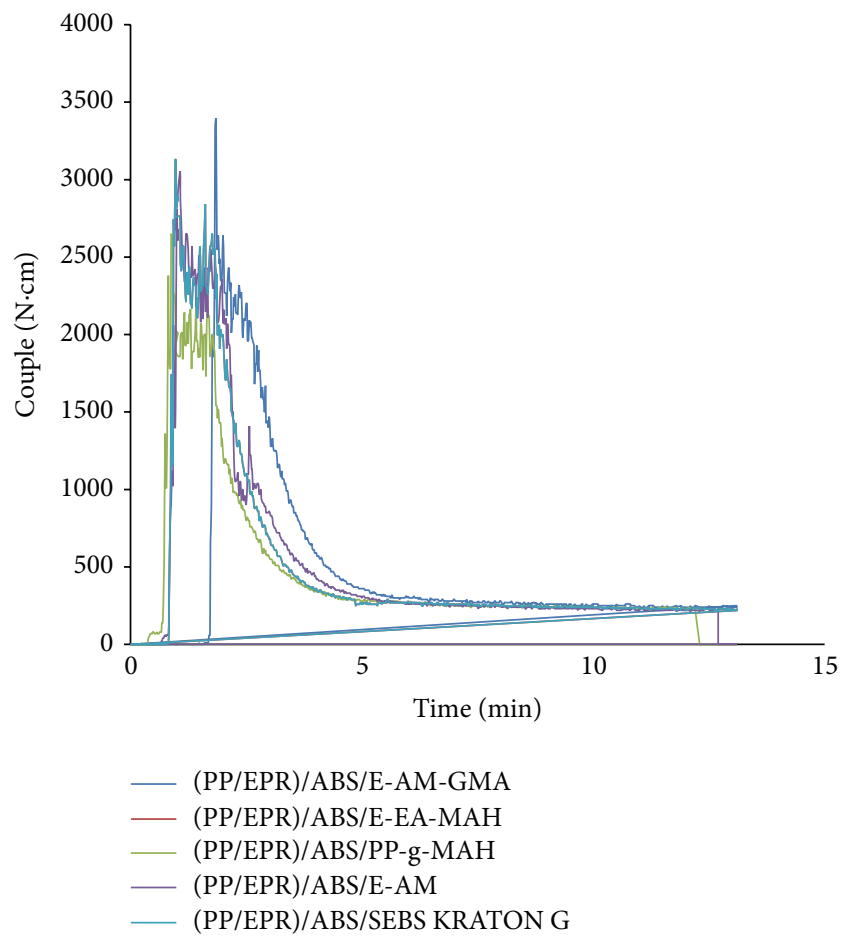

FIGURE 3: Variation of the torque exerted by the screws "rollers" internal mixer HAAKE PolyLab System on mixtures (PP/EPR)/ $\mathrm{ABS} /$ compatibilizers at a rate of $1.5 \%$ of the five compatibilizers.

where $T_{g_{1}}$ and $T_{g_{2}}$ are the glass transition temperatures in Kelvin of the respective homopolymer (component 1 and component 2); $w_{1}$ and $w_{2}$ are the respective weight fractions. So, for EPR statistics, Fox law holds, with $T_{g \mathrm{P}}=289 \mathrm{~K}$ and $T_{g \mathrm{E}}=173 \mathrm{~K}$. From $T_{g}$ of the EPR equal to $232 \mathrm{~K}$, it has been calculated that there are $50 \%$ of -E- sequences and $50 \%$ of -Psequences.

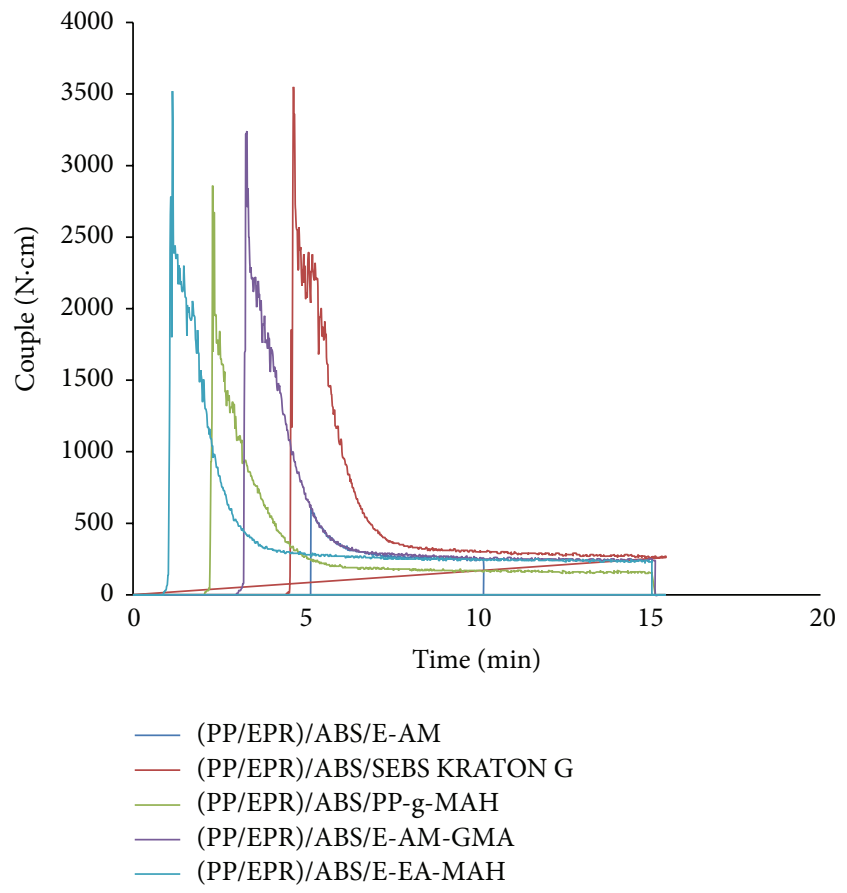

FIGURE 4: Variation of the torque exerted by the screws "rollers" internal mixer HAAKE PolyLab System on mixtures (PP/EPR)/ ABS/compatibilizers at rate of $5 \%$ of each one of the five compatibilizers.

The verification by means of the Fox law confirms that the characteristics of the copolymer PP/EPR respect the standard. In fact, it was perfectly processed by the manufacturer that has fully respected the same ratio of E- and -P- sequences. Figures 3 and 4 show the mixtures (PP/EPR)/ABS, both compatibilized and not. They were not prepared with the same processing conditions. However, the curve profiles and the torque values are almost similar 
TABLE 8: Thermal characteristics of the blends (PP/EPR)/ABS/compatibilizer at rate of $5 \%$ of each one of the five compatibilizers.

\begin{tabular}{lccccccc}
\hline Mixtures & $T_{g \mathrm{ABS}}\left({ }^{\circ} \mathrm{C}\right)$ mid-point & $T_{\mathrm{fE}}\left({ }^{\circ} \mathrm{C}\right)$ & $T_{\mathrm{fP}}\left({ }^{\circ} \mathrm{C}\right)$ & $T_{\mathrm{CE}}\left({ }^{\circ} \mathrm{C}\right)$ & $T_{\mathrm{CP}}\left({ }^{\circ} \mathrm{C}\right)$ & $\Delta \mathrm{Hf}_{p}\left(\mathrm{~J} / \mathrm{g}_{\mathrm{PP}}\right)$ & $\Delta \mathrm{HC} p\left(\mathrm{~J} / \mathrm{g}_{\mathrm{PP}}\right)$ \\
\hline (PP/EPR)/ABS & 105.7 & 116.16 & 170.83 & 93.00 & 124.83 & -104.84 & 106.59 \\
(PP/EPR)/ABS/E-AM-GMA & 105.7 & - & 171.83 & 94.16 & 124.16 & -94.29 & 97.61 \\
(PP/EPR)/ABS/E-EA-MAH & 105.7 & 109.00 & 171.33 & 90.83 & 125.66 & -101.32 & 108.35 \\
(PP/EPR)/ABS/PP-g-MAH & 105.7 & 115.5 & 171.00 & 93.83 & 120.5 & -101.73 & 105.84 \\
(PP/EPR)/ABS/SEBS & 105.7 & 118.16 & 171.83 & 95.83 & 125.5 & -96.88 & 103.24 \\
(PP/EPR)/ABS/E-AM & 105.7 & 116.33 & 172.00 & 93.16 & 124.16 & -98.90 & 103.91 \\
\hline
\end{tabular}

$\Delta \mathrm{Hf}_{p}$ : melting enthalpy of the isotactic polypropylene sequences (-P-) of the basic copolymer PP/EPR.

$\Delta \mathrm{HC}_{p}$ : crystallization enthalpy of the isotactic polypropylene sequences (-P-) of the basic copolymer PP/EPR.

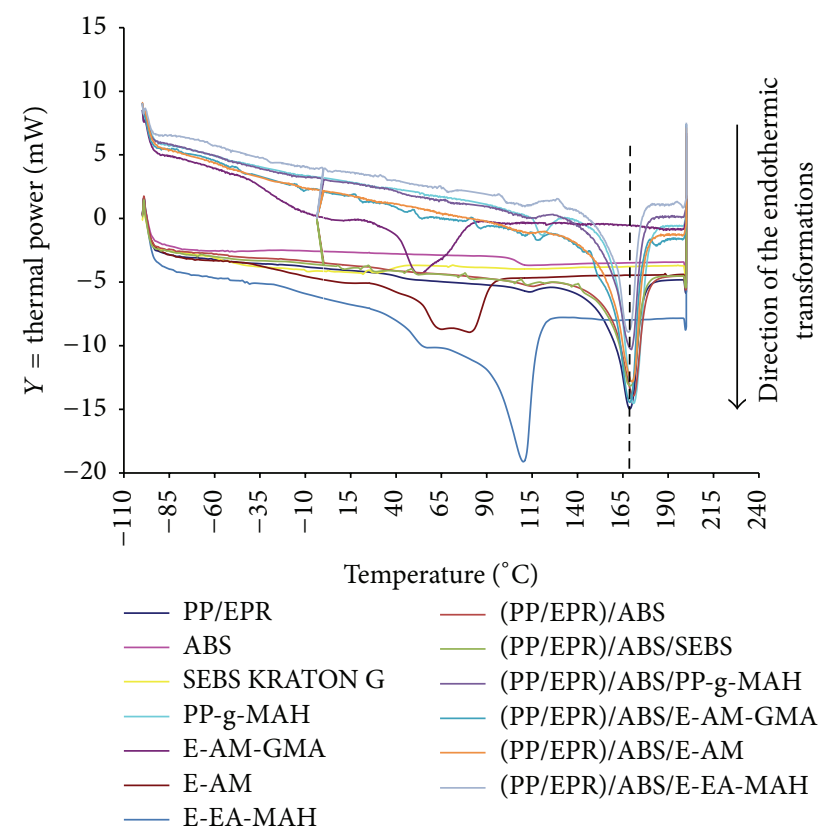

FIGURE 5: DSC curves in the direction of the endothermic transformations of components and mixtures (PP/EPR)/ABS/compatibilizer (93.5)/5/1.5, for the first thermal cycle. For about $15 \mathrm{mg}$ of sample. 1 graduation $Y=5 \mathrm{~mW}$.

regardless of the compatibilizer used and their respective proportion in the mixtures.

\section{Discussion}

The miscible blends are only a minority of cases encountered [14]. Their main advantage is that they allow extending the use of homopolymers window that composes them. Immiscible polymer blends are much more frequent; they are characterized by a multi-phase structure. These blends are generally incompatible, owing to the absence of favorable interactions between the chains of the polymers constituting [21]. Methods for improving the adhesion between the phases, involve the addition of a third body which ensures the control and stabilization of the morphology by reactions or interactions between functions or active sites on each of the phases present. The thermal analyses performed on the different mixtures have demonstrated the goodness and the efficiency of this technique. Figure 1 gives the thermal properties of the

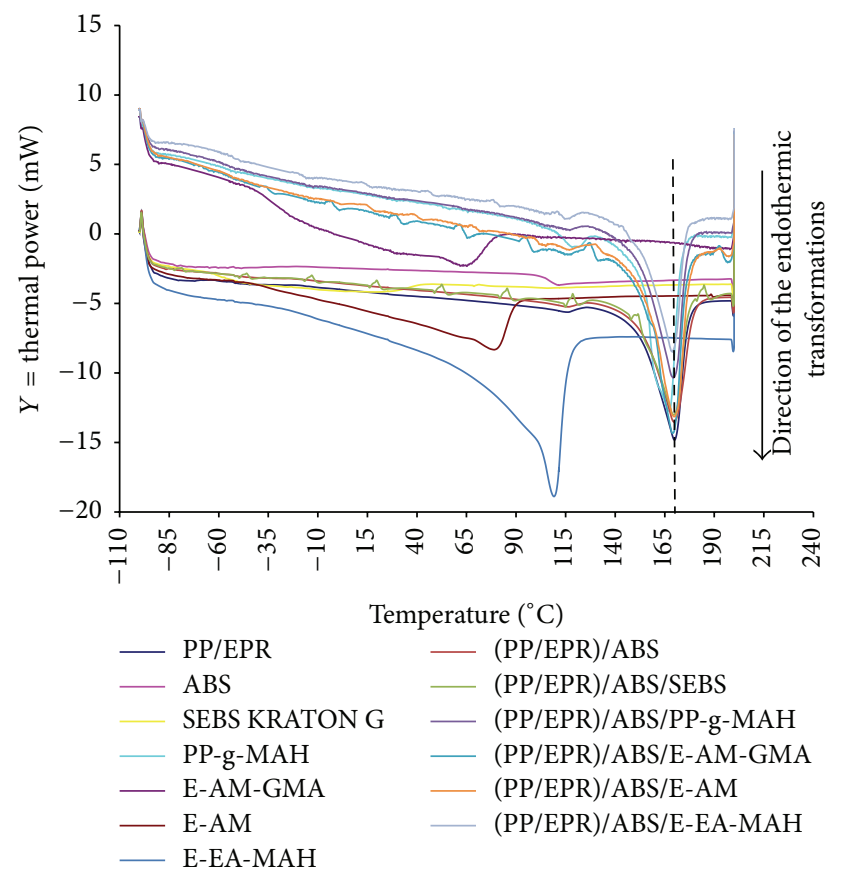

FIGURE 6: DSC curves in the direction of the endothermic transformations of components and mixtures (PP/EPR)/ABS/compatibilizer (93.5)/5/1.5, for the second thermal cycle. For about $15 \mathrm{mg}$ of sample. 1 graduation $Y=5 \mathrm{~mW}$.

PP/EPR mixture where the transition temperature and melting temperature values appear at 115 and $170^{\circ} \mathrm{C}$ respectively. The uniformity of the shape of the melting peak argues in a relatively good compatibility between the two components. During cooling it has been observed that the recrystallization temperature, $125^{\circ} \mathrm{C}$, occurs at a much lower temperature than that of melting. The same effect can be observed for the transition temperature which occurs at $93^{\circ} \mathrm{C}$ instead of $115^{\circ} \mathrm{C}$ when heating. This retardation in the apparition of these singular transitions can be attributed to the difference in the thermal properties of the respective polymer. PP is a thermoplastic material having a melting temperature around $165^{\circ} \mathrm{C}$, while the EPR is commonly a thermoset giving to the mixture a particular thermal behavior.

The DSC curves of ABS (Figure 2) do not show specific transitions excepting $T_{g}$ at around $115^{\circ} \mathrm{C}$. The absence of a melting peak argues in favor of the absence of a well-defined 


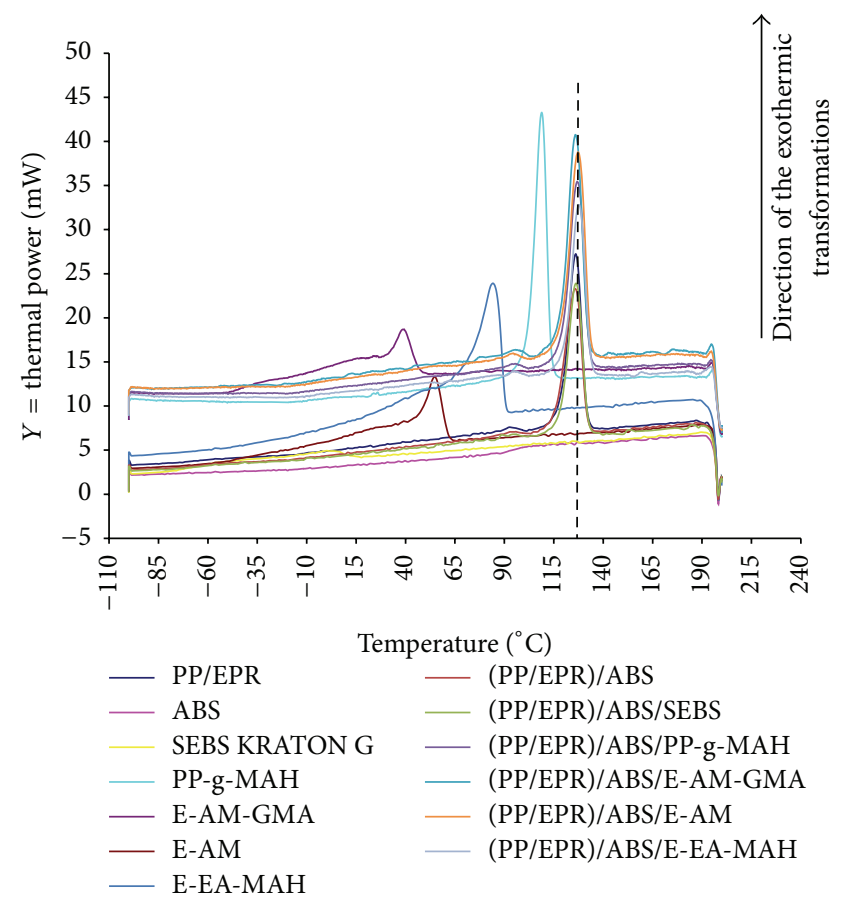

FIGURE 7: DSC curves in the direction of the exothermic transformations of components and mixtures (PP/EPR)/ABS/compatibilizer (93.5)/5/1.5, for the first thermal cycle. For about $15 \mathrm{mg}$ of sample. 1 graduation $Y=5 \mathrm{~mW}$.

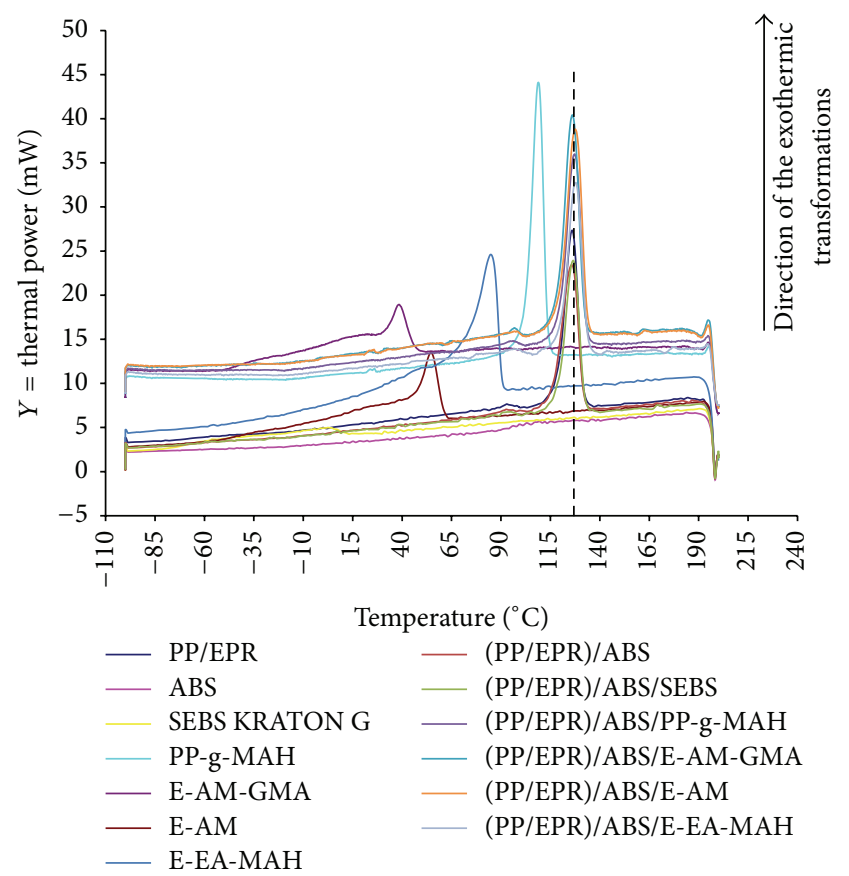

FIGURE 8: DSC curves in the direction of the exothermic transformations of components and mixtures (PP/EPR)/ABS/compatibilizer (93.5)/5/1.5, for the second thermal cycle. For about $15 \mathrm{mg}$ of sample. 1 graduation $Y=5 \mathrm{~mW}$.

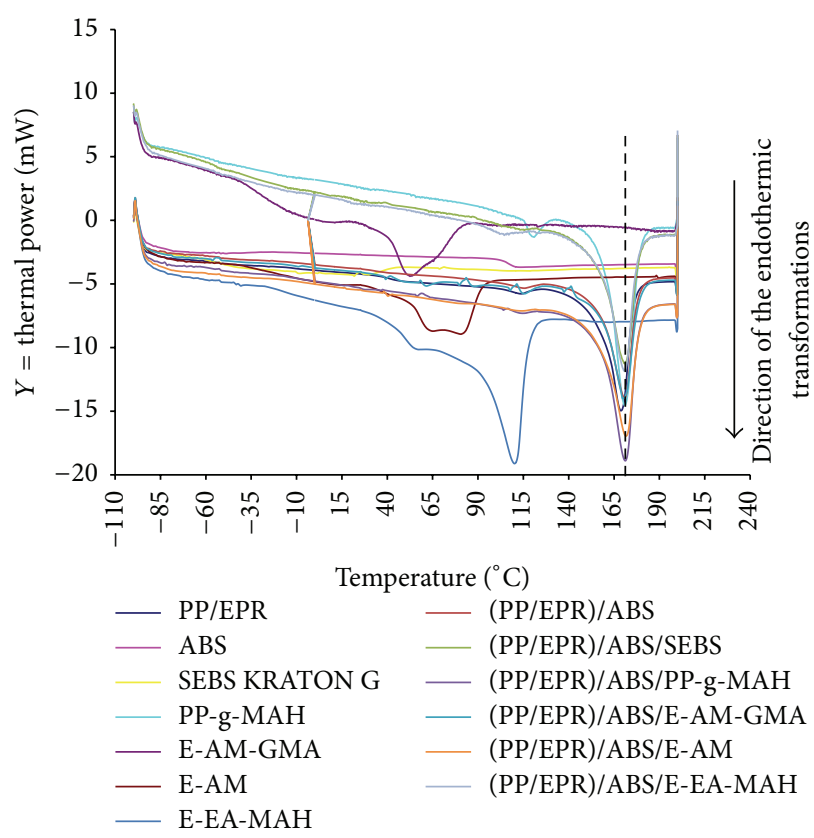

FIGURE 9: DSC curves in the direction of the endothermic transformations of components and mixtures (PP/EPR)/ABS/compatibilizer (95)/5/5, for the first thermal cycle. For about $15 \mathrm{mg}$ of sample. 1 graduation $Y=5 \mathrm{~mW}$.

crystalline phase, meaning that this material is rather highly amorphous.

Figures 3 and 4 show the evolution of the blends homogeneity with time. It appears clearly that the higher the rate of compatibilizer is the longer the time to reach the maximum torque is. The three main effects sought in the recognition of a mixture are the following [14]:

(i) Reduction of interfacial tension to facilitate the dispersion.

(ii) Stabilization of the morphology to avoid changing it during processing steps and implementation of the material.

(iii) Increased adhesion between phases in the solid state in order to promote in particular the stress transfer between the phases and thus improve the mechanical properties of the mixture.

Depending on the chosen method of accounting and the type of compatibilizer used, each of the three previous objectives can be more or less achieved. The two most frequently used strategies in the compatibilization of immiscible polymer blends strategies are the following [14]:

(i) The addition of a preformed copolymer, nature, and suitable structures capable of interacting with each of the phases present.

(ii) In situ formation of a copolymer by chemical reaction at the interface between the phases during preparation of the mixture.

For blends compatibilized, the choice of compatibilizer is based on the miscibility of the sequences of the latter 


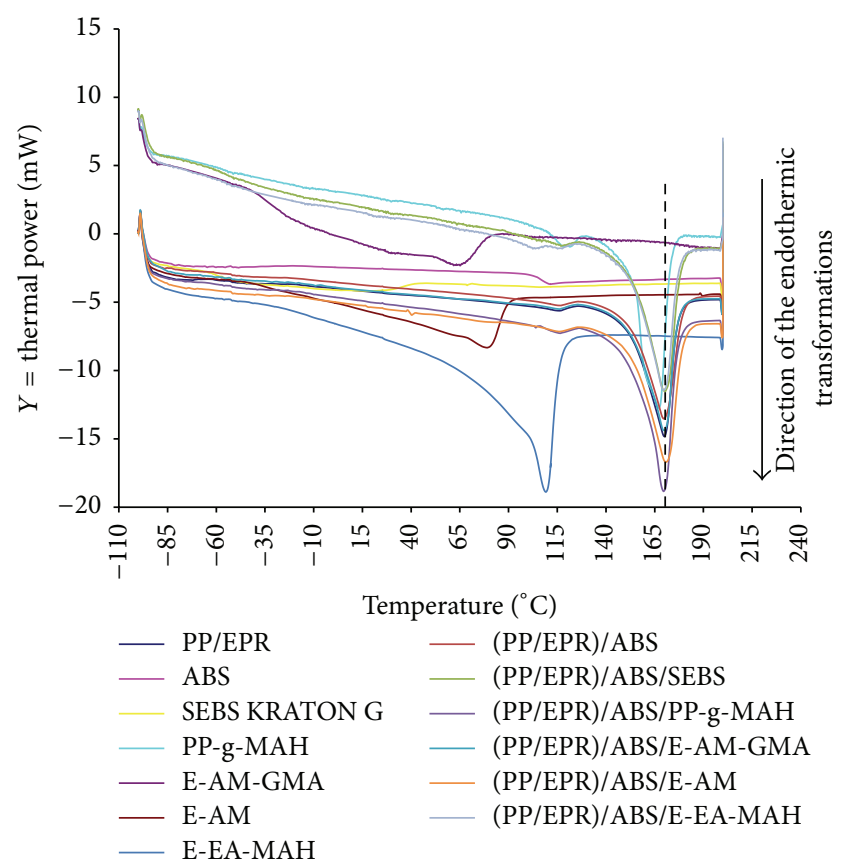

FIGURE 10: DSC curves in the direction of the endothermic transformations of components and mixtures (PP/EPR)/ABS/compatibilizer (95)/5/5, for the second thermal cycle. For about $15 \mathrm{mg}$ of sample. 1 graduation $Y=5 \mathrm{~mW}$.

with the mixture components. Similarly, the low molecular weight chains of the compatibilizer will facilitate their diffusion in the molten medium (high viscosity) and will focus their accessibility and their concentration on the areas of interaction, that is, the interface between the two-phase mixture [22]. The solubility of the sequences in compatibilizing homopolymer is a key factor [21-26]; it controls the morphology of the mixture, its stability, and adherence to the interface.

It is observed that with $1.5 \%$ of compatibilizer the homogenization of the blend takes a mean time of four minutes. But, with $5 \%$, the homogenization is accelerated and occurs in three minutes or less. This variation of the mean time for the homogenization shows that the compatibilizer promotes effectively and efficiently the blending of the mixture.

Figures 5 and 6 show the DSC curves in the direction of the endothermic transformations of components and mixtures (PP/EPR)/ABS/compatibilizer (93.5)/5/1.5, for the first and the second thermal cycles, respectively. It is observed that the DSC curves display almost the same aspect according to the melting temperature regardless of the thermal cycle (first or second). However, it could be still noticed that the mixture (PP/EPR)/ABS shows a well-defined endothermic peak in the temperatures range of $140-190^{\circ} \mathrm{C}$ with a maximum around $173^{\circ} \mathrm{C}$. The mixture E-AM-GMA does not have a melting peak as the others around $165^{\circ} \mathrm{C}$. A small drop of the base line in the temperature range of -35 to $90^{\circ} \mathrm{C}$ with a maximum around $50^{\circ} \mathrm{C}$ can still be observed. The same kind of observation can be done for the mixture E-AM, except that the maximum has slightly shifted to higher values and the bottom of the peak let two maxima appear: the first around $60^{\circ} \mathrm{C}$ and the

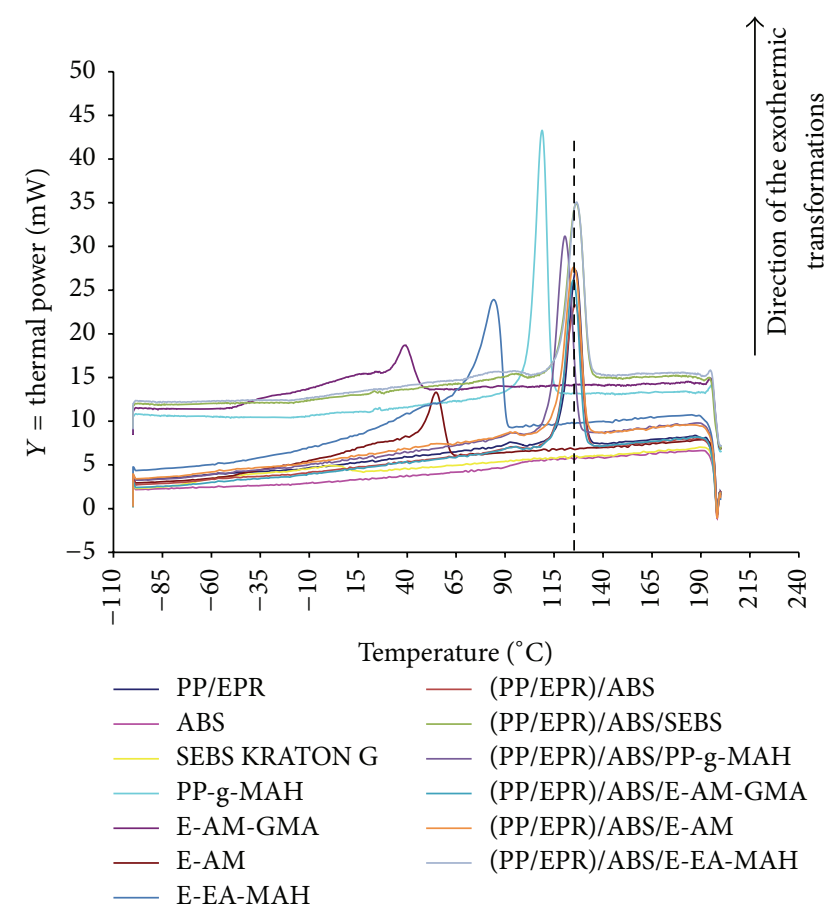

FIGURE 11: DSC curves in the direction of the exothermic transformations of components and mixtures (PP/EPR)/ABS/compatibilizer (95)/5/5, for the first thermal cycle. For about $15 \mathrm{mg}$ of sample. 1 graduation $Y=5 \mathrm{~mW}$.

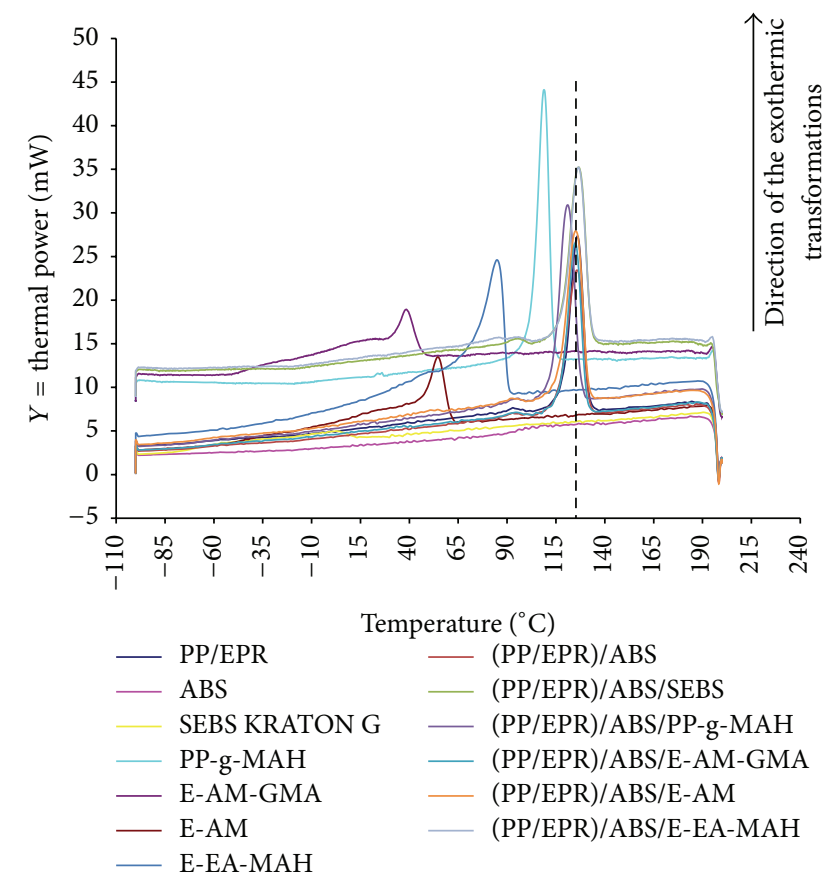

FIgURE 12: DSC curves in the direction of the exothermic transformations of components and mixtures (PP/EPR)/ABS/compatibilizer (95)/5/5, for the second thermal cycle. For about $15 \mathrm{mg}$ of sample. 1 graduation $Y=5 \mathrm{~mW}$. 
second close to $80^{\circ} \mathrm{C}$. The mixture E-EA-MAH also shows a singular behavior in comparison to the other mixtures since its melting occurs earlier at about $115^{\circ}$. For all the others it appears well above, that is, around $165^{\circ} \mathrm{C}$. During the cooling cycles the mixture PP-g-MAH shows a singular behavior: the peak of recrystallization shifts to lower temperature (i.e., $\left.\approx 100^{\circ} \mathrm{C}\right)$ compared to that of the other mixtures $\left(\approx 115^{\circ} \mathrm{C}\right)$ (Figures 7 and 8).

For the rest of the experiments (variation of the compatibilizers concentration, first and second thermal cycles) these previous remarks and differences remain almost true.

Figures 9 and 10 present the DSC curves in the direction of the endothermic transformations of components and mixtures (PP/EPR)/ABS/compatibilizer (95)/5/5, for the first and the second thermal cycles, respectively. Figures 11 and 12 show the DSC curves in the direction of the exothermic transformations of components and mixtures (PP/EPR)/ABS/compatibilizer (95)/5/5, for the first and the second thermal cycles, respectively. The same observations done for the first series of test can be done for the second one. It is observed that melting temperatures for all compatibilized blends or mixtures are perfectly aligned for endothermic transformations, except for the first thermal cycle of mixture (PP/EPR)/ABS/compatibilizer (93.5)/5/1.5. It is at the same time observed that the second thermal cycles have a correct effect. It is also stated that the improvement of the rate of compatibilizer has a correct effect on melting temperatures.

For the endothermic transformations, the predominant peaks tend to have the most important enthalpy values of fusion for -P-sequences as reported in the tables. This might be due to the fact that blends have almost the same melting temperature, and then the thermal power is mainly governed by the melting enthalpy values of the -P-sequences regardless of PP-g-MAH.

Observing our results, a small increase in crystallization temperature for all mixtures at a low rate of compatibilizer emerges. In our maximum rate, the behavior is completely random. In the case of the exothermic transformations and regardless of the thermal cycle, the lower rate of compatibilizer tends to perfectly align the crystallization temperatures of the blend. On the contrary, the opposite effect can be observed when the compatibilizer rate is increased.

It can be still noticed that, in general, the DSC curves keep their global initial aspect. Then it can be stated that the incorporation of $5 \%$ of $\mathrm{ABS}$ in the copolymer PP/EPR does not significantly affect the thermal properties of the basic copolymer; the addition of $1.5 \%$ of each compatibilizer in the basic mixture does not significantly alter the crystallization temperature values and melting of the -P- sequences. However, there is a variation of the melting enthalpy values of the -P- sequences of $18.23 \%$ using SEBS KRATON G and of $10.38 \%$ using the E-AM-GMA; with regard to the crystallization enthalpies of the -P- sequences, only the PPg-MAH allows observing a variation of $8.59 \%$. At last, when the rate of each compatibilizer increases by $5 \%$, the overall crystallization enthalpy of the -P- sequences remains almost unchanged, except for the case when using the compatibilizer E-AM-GMA with a variation of $8.42 \%$. It has also been observed that, for the presence of high concentration of compatibilizer, the melting enthalpy of the -P- sequences varies less. The addition of $5 \%$ of ABS copolymer to PP/EPR does not affect significantly the thermal properties of the basic (PP/EPR)/ABS mixture.

\section{Conclusions}

This work has been devoted to the effects of the addition of compatibilizers on the thermal properties of the polymeric mixture (PP/EPR)/ABS. The addition of $5 \%$ of ABS to the $\mathrm{PP} / \mathrm{EPR}$ copolymer does not significantly affect the thermal properties (enthalpies, melting temperatures, and crystallization) of the basic copolymer. In the same time, the addition of $1.5 \%$ of each compatibilizer in the basic mixture does not affect significantly the crystallization temperature values. The same kinds of observations have been made for the melting temperatures of the -P- sequences. However, a variation of the melting enthalpy values of the -P- sequences of about $18.23 \%$ when using SEBS KRATON G and $10.38 \%$ when using the E-AM-GMA is still observable. For the crystallization enthalpies of the -P- sequences, only the PP-g-MAH allows variation of $8.59 \%$. When the rate of each compatibilizer increases up to $5 \%$, the overall crystallization enthalpies of the -P- sequences remain almost unchanged except in the case when the E-AM-GMA compatibilizer is used with a variation of $8.42 \%$. It has also been observed that, with high levels of compatibilizer, the melting enthalpy of the -P- sequences varies less; however, the compatibilizer E-AM-GMA is the one that causes the greatest variation with a value of $10 \%$.

\section{Abbreviations}

\author{
E-EA-MAH: LOTADER AX3210 \\ E-AM-GMA: LOTADER AX8900 \\ E-AM: $\quad$ LOTRYL ECH 20MA08 \\ PP-g-MAH: OREVAC CA 100 \\ PP/EPR: $\quad$ PP108MF97 marketed by SABIC.
}

\section{Industrial Names Copolymers}

PP:

EPR:

SAN:

ABS:

E-EA-MAH: Triblock Ethylene Ester-Acrylic

$$
\text { Polypropylene (isotactic) }
$$

Ethylene propylene rubber

Styrene copolymer/acrylonitrile

E-AM-GMA: Ethylene/Acrylatemethyl/Glycidyl Methacrylate

E-AM: $\quad$ Ethylene Acrylate Methyl copolymer

SEBS KRATON G: Triblock Copolymer poly(styrene-b-

ethylene-co-butylene-b-styrene

PP-g-MAH: Polypropylene-g-Anhydride

DSC: $\quad$ Differential Scanning Calorimetry.

\section{Conflict of Interests}

The authors declare that there is no conflict of interests regarding the publication of this paper. 


\section{References}

[1] L. Robeson, "Historical perspective of advances in the science and technology of polymer blends," Polymers, vol. 6, no. 5, pp. 1251-1265, 2014.

[2] G. P. Simon, Polymer Characterization Techniques and Their Application to Blends, Oxford University Press, New York, NY, USA, 2003.

[3] W. Baker, C. Scott, and G. H. Hu, Reactive Polymer Blending, Hanser Publishers, Munich, Germany, 2001.

[4] D. R. Paul and C. B. Bucknall, Polymer Blends, Volume 1 (Formulation) and Volume 2 (Performance), John Wiley \& Sons, New York, NY, USA, 2000.

[5] L. A. Utracki, Polymer Blends Handbook, vol. 1-2, Kluwer Academic, Dordrecht, The Netherlands, 2002.

[6] L. Utracki, Polymer Alloys and Bleds. Thermodynamics and Rheology: Part 1, Hanser, Munich, Germany, 1989.

[7] D. Paul and C. Bucknall, Introduction in Polymer Blends: Formulation, vol. 1, Wiley-Interscience, New York, NY, USA, 2000, edited by: D. R. Paul, C. E. Bucknall.

[8] L. Utracki, Commercial Polymer Blends, vol. 1, Chapman Hall, London, UK, 1998.

[9] N. P. M. Anicet, A. O. Louis-Max, E. M. Roland, C. Salem, and A. Z. Merlin, "Study of thermal properties of mixed (PP/EPR)/calcium carbonates," Indian Journal of Science \& Technology, vol. 8, no. 11, Article ID 51675, 2015.

[10] D. M. Kulich, “ABS resins," in Encyclopedia of Chemical Technology, O. Kirk, Ed., vol. 1, pp. 391-411, John Wiley \& Sons, New York, NY, USA, 1993.

[11] D. M. Kulich, P. D. Kelly, and J. E. Pace, Encyclopedia of Polymer Science and Engineering, vol. 1, John Wiley \& Sons, New York, NY, USA, 1985.

[12] I. I. Rubin, Handbook of Plastic Materials and Technology, edited by: I. Irvin, Wiley, New York, NY, USA, 1990.

[13] H. Blom, R. Yeh, R. Wojnarowski, and M. Ling, "Detection of degradation of ABS materials via DSC," Thermochimica Acta, vol. 442, no. 1-2, pp. 64-66, 2006.

[14] M. Nizar, Elaboration et caractérisation de mélanges complexes à base de polypropylène en vue de son écoconception et de son recyclage dans les véhicules hors d'usage [Ph.D. thesis], Institut National des Sciences Appliquées de Lyon, Villeurbanne, France, 2008.

[15] G.-X. Wei, H.-J. Sue, J. Chu, C. Huang, and K. Gong, “Toughening and strengthening of polypropylene using the rigidrigid polymer toughening concept. Part I. Morphology and mechanical property investigations," Polymer, vol. 41, no. 8, pp. 2947-2960, 2000.

[16] A. Eisenberg, Physical Properties of Polymers, ACS, Washington, DC, USA, 1984.

[17] C. Lorenzetti, L. Finelli, N. Lotti et al., "Synthesis and characterization of poly(propylene terephthalate/2,6-naphthalate) random copolyesters," Polymer, vol. 46, no. 12, pp. 4041-4051, 2005.

[18] G. Fox, "Prediction of glass transition temperatures," Bulletin of the American Physical Society, vol. 1, p. 123, 1956.

[19] P. Marchese, A. Celli, M. Fiorini, and M. Gabaldi, "Effects of annealing on crystallinity and phase behaviour of PET/PC block copolymers," European Polymer Journal, vol. 39, no. 6, pp. 1081-1089, 2003.
[20] N. Cameron, J. M. G. Cowie, R. Ferguson, J. L. Gómez Ribelles, and J. Más Estellés, "Transition from miscibility to immiscibility in blends of poly(methyl methacrylate) and styreneacrylonitrile copolymers with varying copolymer composition: a DSC study," European Polymer Journal, vol. 38, no. 3, pp. 597605, 2002.

[21] A. Colbeaux, Compatibilisation de mélanges polypropylène/polyéthylène par extrusion réactive [Ph.D. thesis], Institut National des Sciences Appliquées de Lyon, Villeurbanne, France, 2001.

[22] L. Utracki, Commercial Polymer Blends, Chapman Hall, London, UK, 1998.

[23] P. S. Tucker and D. R. Paul, "Simple model for enthalpic effects in homopolymer/block copolymer blends," Macromolecules, vol. 21, no. 9, pp. 2801-2807, 1988.

[24] K. M. Hong and J. Noolandi, "Theory of phase equilibria in systems containing block copolymers," Macromolecules, vol. 16, no. 7, pp. 1083-1093, 1983.

[25] D. J. Meier, Preprint, Polymer Colloquium on Polymer Science, Tokyo, Japan, p. 83, 1977.

[26] M. D. Whitmore and J. Noolandi, "Theory of phase equilibria in block copolymer-homopolymer blends," Macromolecules, vol. 18, no. 12, pp. 2486-2497, 1985. 


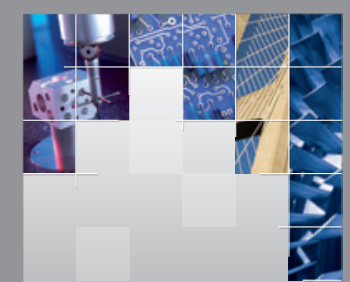

\section{Enfincering}
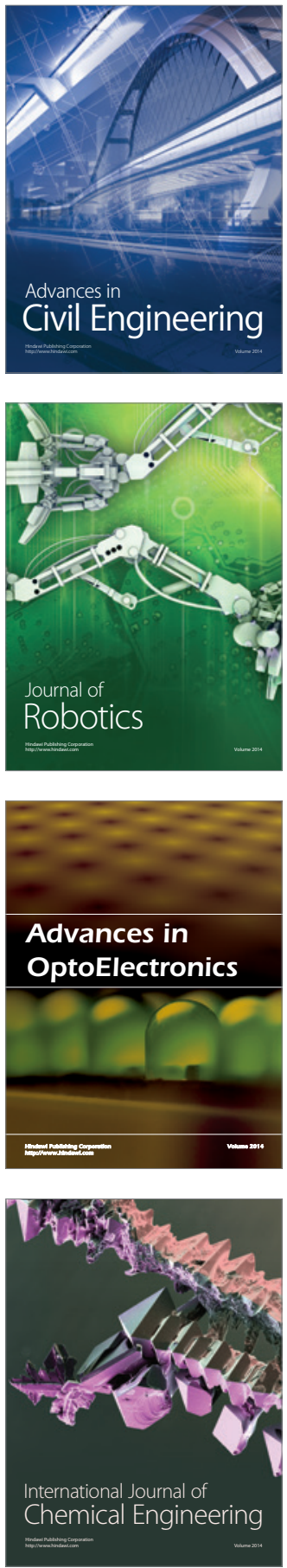

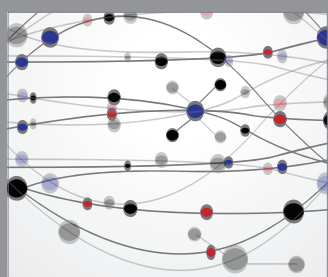

The Scientific World Journal

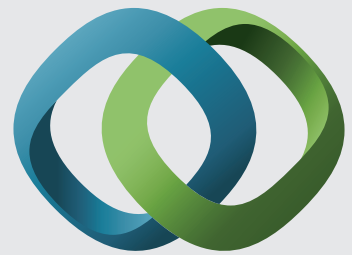

\section{Hindawi}

Submit your manuscripts at

http://www.hindawi.com
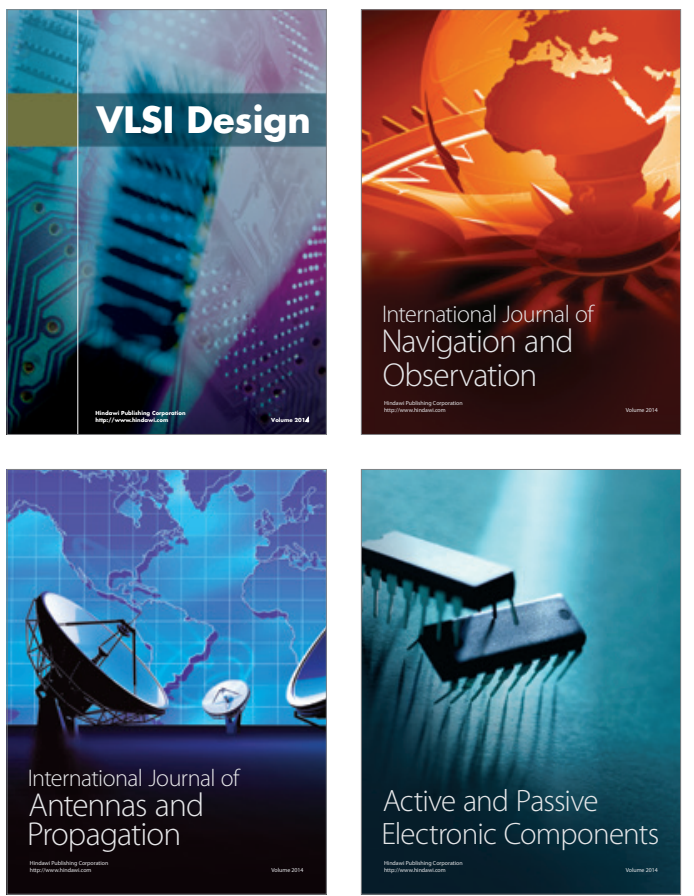
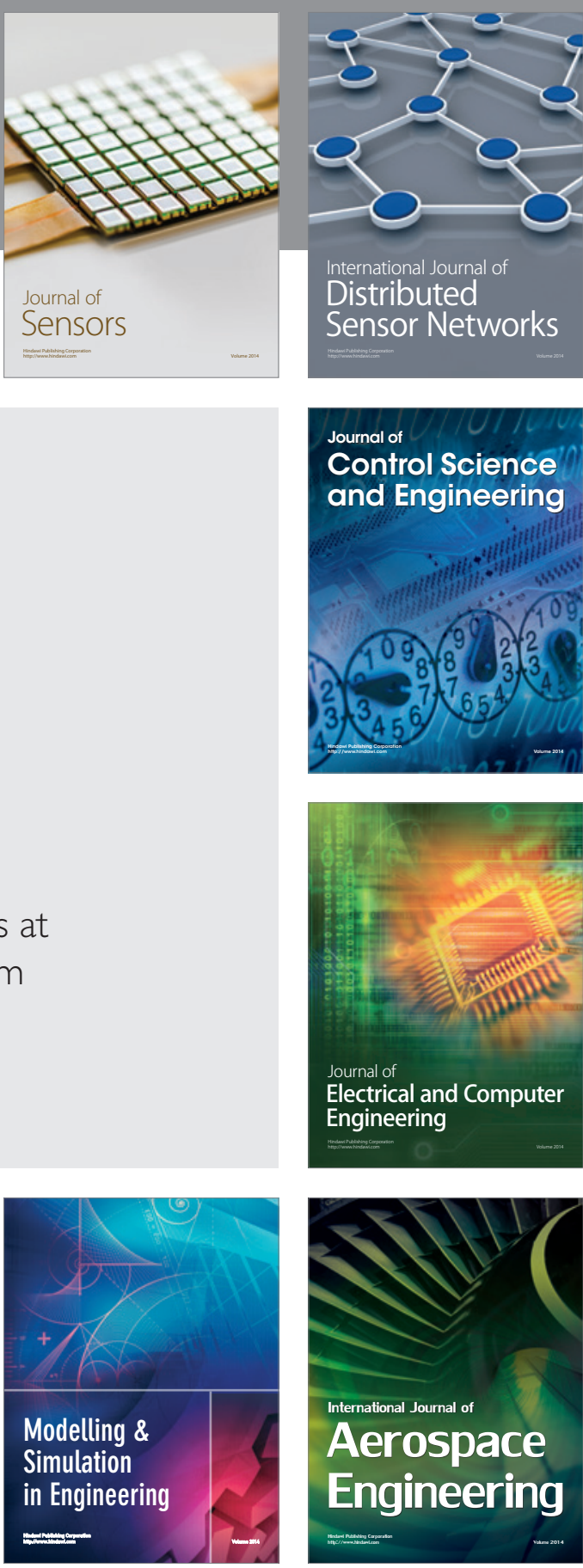

International Journal of

Distributed

Sensor Networks

Journal of

Control Science

and Engineering
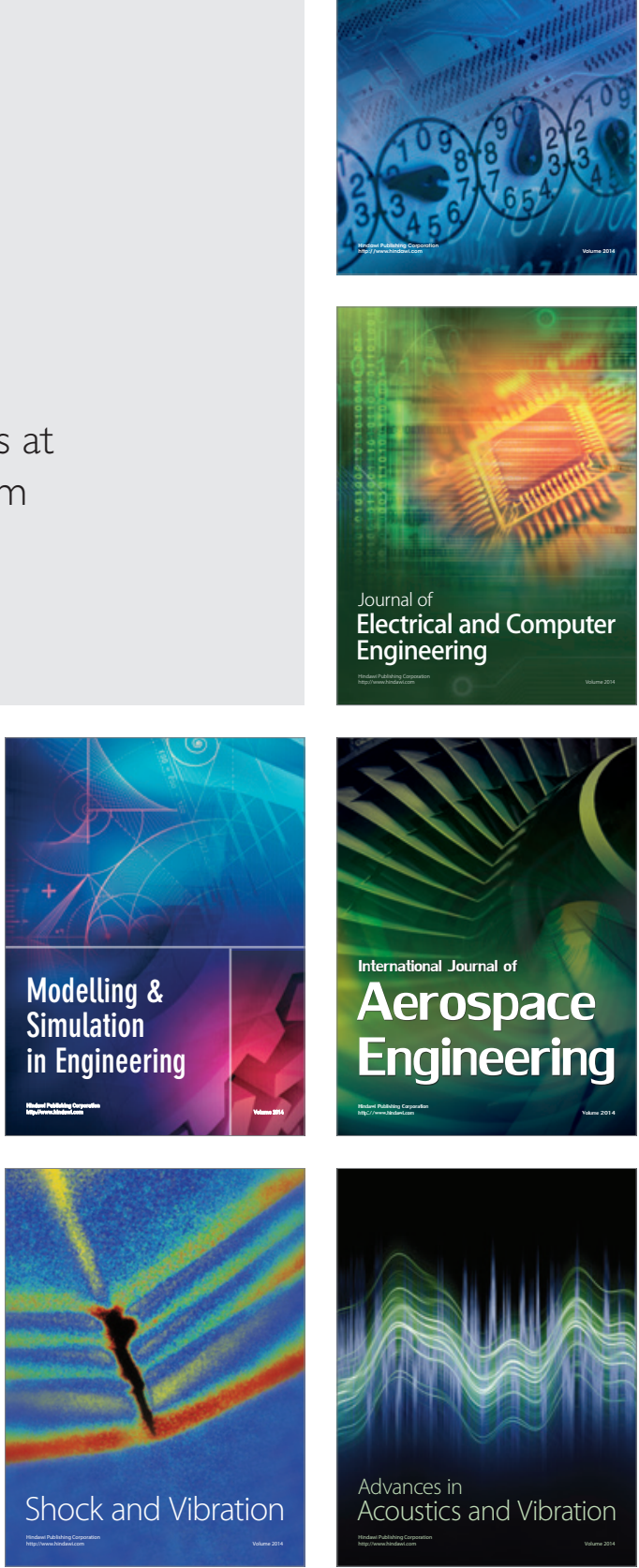